\title{
Fostering Innovation of Thinking for Student-Facing Mathematics Difficulty Through Commercial Sport Video Games
}

\author{
Herfa Maulina Dewi Soewardini \\ Universitas Negeri Surabaya, Indonesia \\ herfa.19008@mhs.unesa.ac.id \\ Hery Setiyawan \\ Universitas Wijaya Kusuma Surabaya, Indonesia \\ heri.setiyawan_fbs@uwks.ac.id \\ Dwi Juniati \\ Universitas Negeri Surabaya, Indonesia \\ dwijuniati@unesa.ac.id \\ Siti Khabibah \\ Universitas Negeri Surabaya, Indonesia \\ sitikhabibah@unesa.ac.id \\ Abdul Talib bin Bon University \\ Tun Hussein Onn Malaysia \\ talibon@gmail.com
}

\begin{abstract}
Every student likes a game that can keep him entertained by the many lessons at school. When they find it difficult to understand mathematical concepts in class, they tend not to show innovation in thinking when completing practice questions. Students mostly access video games via smartphones to forget learning difficulties. Furthermore, designed digital audio media related to sports and that obtained by students, namely commercial sports video games. From the results of the study, it turns out students who play commercial sports video games show innovative thinking skills, more comfortable to learn concepts, and enjoy mathematics. They can interpret according to what is in the scheme and written using a mathematical model.
\end{abstract}

Keywords: innovation thinking, video games, mathematics difficulty

\section{INTRODUCTION}

The lives of children and adolescents often struggle with video games played at least one hour per day. Playing video games turns out to have psychosocial benefits in the real world and has a positive effect seen from the cognitive, motivational, emotional, and social dimensions (Granic, Lobel, \& Engels, 2014). Playing video games is beneficial for children to be able to process information in the brain, increase student motivation, train emotionally, and have a social responsibility.

Learning by playing can trigger children to be more comfortable and interested in learning. The child is not only a kindergarten student but also an elementary and middle school student. Previous research indicated that playing video games can develop cognitive abilities such as learning and literacy. Examples: students who want to escape to the forest through the labyrinth, and there are many other examples ("What Video Games Have to Teach Us about Learning and Literacy," 2004).

The ability to think innovatively can also arise in the use of video games media. This ability was constructing mathematics modeling and stated problem-solving that appear in the 
display as well as examples of video games themes such as sports. In this case, commercial sport video games can be accessed online via YouTube. Youtube viewed by the academic community or the school community because many have video tutorials, video games, and music videos that have an attractive and entertaining audio-visual display.

Student mathematics learning experience is more in solving problems, but there are still many students who face difficulty solving problems. Students are not able to model mathematical problems encountered such as writing mathematical formulas or equations, even writing down what is known and asked. Therefore they become more interested in playing than learning, which can be seen from activities using a smartphone while studying. With this exciting learning experience, the use of digital-based knowledge can provide real situations at home or school. Also, the experience of playing video games can increase selective visual attention (Sadera, $\mathrm{Li}$, Song, \& Liu, 2014).

The purpose of this study is to describe the efforts in fostering innovative thinking skills for students who face the difficulties of learning mathematics through commercial sport video games.

Creative thinking is central to the arts, sciences, and everyday life. Also, original thought involves dynamic interactions of large-scale brain systems (Beaty, Benedek, Silvia, \& Schacter, 2016). Our brain system consists of nerves that are related to each other. To be able to support the thought process, the brain's network is very encouraging cognitive processes that are very complex. One example of this highly complex cognitive process is creative thinking.

Creative thinking in everyday life can make it easier for us to adapt to new experiences, especially in learning. The abilities related to creativity in education are as follows:

1. Able to develop, implement, and convey new ideas orally and in writing.

2. Be open to new and different perspectives.

3. Expressing creative ideas conceptually and practically.

4. Using concepts or knowledge in new and different situations.

5. Able to create novelty based on the initial knowledge possessed by innovative thinking.

6. Able to adapt to new conditions and positive contributions.

Creative thinking in mathematics is using mathematical logic and divergent thinking based on intuition but still aware that it has a purpose. Divergent thinking focuses on flexibility, fluency, and novelty in the submission and solving of mathematical problems (Siswono, 2010).

In this case, the ability to think innovatively can emerge if creativity also arises. Think innovative means that students can create novelty based on fundamental knowledge and new information obtained from various sources, both offline and online. Besides, it is flexible to multiple types of things that found associated with the scheme. Also, fluent in understanding mathematical problems along with mathematical modeling.

Innovation in the learning process is related to experience, reflection, thinking, and acting (Beckman \& Barry, 2007). All things experienced in learning both interactions between students, also students and teachers can make students believe in the scheme. Furthermore, it reflects what happened, strengths, and weaknesses and what needs to fix. Finally, acting under the intuition, thus fostering innovation in the thought process.

In creativity No. 5, the statement that students can create novelty based on the initial knowledge possessed, so-called innovative thinking. Innovative showed if students can describe the similarities and differences from videos 1 and 2. Second, students can create variables based on what did they see in the videos. Third, students can develop mathematical models of variables that have made. Finally, they can determine solutions from mathematical models that have been prepared to keep in mind previous knowledge in the scheme.

There are still many students who have difficulty learning mathematics, including generating ideas as a high-level thinking activity. Also, they have difficulty in proposing and solving problems, manipulating concepts, developing mathematical modeling, and others.

In previous studies, also mentioned difficulties in constructing evidence using definitions, theorems, and manipulating concepts (Weber, 2002). If they can manipulate it, the construction of proof will be arranged systematically and in detail which contains the stages and reasons.

For the use of instructional media, students also find it difficult to understand concepts if 
This work is licensed under a Creative Commons Attribution- ShareAlike 4.0 International License.

the teacher does not use teaching aids. Also, the display of powerpoints whether or not there is audio. Students at the formal operational stage (Ojose, B. (2008). Applying Piaget's theory of cognitive development to mathematics instruction. The Mathematics Educator, 2008) theoretically don't need concrete objects as learning tools. But, in fact, they still need to use teaching aids to be able to retell the concepts explained by the teacher.

Learning difficulties also arise from within students such as boredom, dislike, lack of confidence, anxiety, and many others (Brown, Brown, \& Bibby, 2008). These difficulties can occur because there are triggers from the surrounding environment, such as schools, family environments, or the community.

Not only children, but adults also like games. The game that developed at this time is a video game that is loved by all circles. Video games are a medium that is entertainment for its users like toys that are shaped and can manipulate. Games that can be accessed offline and online have a lot of topics to choose from, one of which is sports.

Sport video games are popular because there is no need to play by coming to the field or sports venue but enough at home or wherever. Many school students like video games because they also access them from smartphones by viewing online via Youtube or offline from the downloads from Youtube.

The rapid development of technology also allows the existence of commercial sports video games which paid advertisements for an advertising company. Also, the company that sells goods and makes advertisements for the product. Usually, commercial sports video games appear when students access YouTube.

In the 21st century mathematical journal, there is a statement about commercial sports video games designed not only for entertainment but also for education. It can improve student achievement, confidence, and comfort in learning mathematics (Phaire, 2001). This improvement happened when students are asked to watch the video in 20-40 seconds. They describe the meaning of the activities displayed, compile mathematical modeling, and check whether or not there is a problem-solving in the video.

Students' perceptions of video games used in learning are aspects of usefulness that make students not bored. The ease of using video games also accessed online via mobile phone. Also, the perception that was having the same learning opportunities and personal experience of each student can be different after seeing the content of the video games (Bourgonjon, Valcke, Soetaert, \& Schellens, 2010).

\section{RESEARCH METHODS}

This research is qualitative. A case study approach used to dig depth information from eighth-graders students. They are using learning technology in the form of digital audio media in the form of video games that can be accessed online via Youtube. Case studies are used to gain in-depth knowledge about the symptoms of students who have difficulty learning mathematics. Then they had treatment of learning through commercial sports video games to foster innovative thinking skills.

The research subjects used were three eighth grade students at SMPN 16 Surabaya. All have excellent communication skills, love sports, and enjoy playing video games and have difficulty learning mathematics. The three students categorized from a high, medium, and low level of difficulty. One student who has a high level, one student who has a medium level, and one student who has a low level.

By case study research conducted in some instances and certain subjects (Timmons \& Cairns, 2010), the research design used is as follows. 


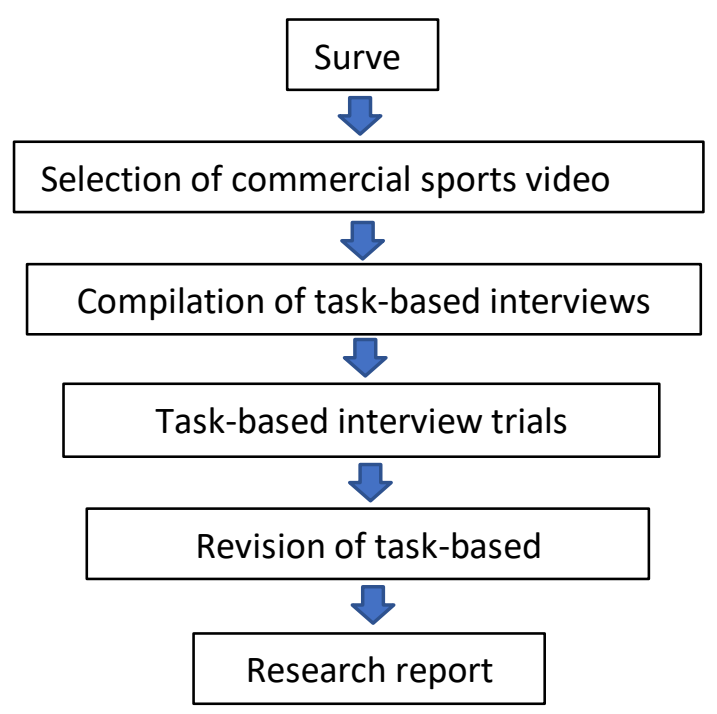

Figure 1. Design of research

\section{School survey}

Researchers went to the schools that would be tested to find out the students 'initial abilities, students' study habits, and sports hobbies as well as playing video games.

\section{Selection of commercial sports video games}

From the survey results, the initial ability, study habits, and sports hobbies or playing video games

\section{Compilation of task-based interviews}

A task-based interview guides when playing video games. the questions about what mathematical topics are appropriate, mathematical modeling that compiled, and or solving problems that may exist.

\section{Task-based interview trials}

Based on the school survey, several commercial sports video games were played and shown to several students according to the category of learning difficulties and sports hobbies in one test school. Next, they interviewed according to the guidelines and tasks that had prepared previously.

\section{Revision of task-based interviews}

This task-based interview revision carried out if the analysis of the results of the trials shows that students have not yet seen innovative thinking abilities.

\section{Research report}

The results of the study had demonstrated creative thinking skills for students with different level of difficulty. They were learning through commercial sport video games on how to learn meaningfully. From the results of the study collected in the interview answers recorded audiovisual from a smartphone, then analyzed with the following steps:

1. Data reduction

The results of task-based interviews are selected, simplified, abstracted, and transformed from data in the field.

2. Presentation of data

From the decline of the data, it is present in the form of interview interviews between researchers.

3. Drawing conclusions

Conclusions had drawn when each interview excerpt contains the desired content about commercial sports video games, innovative thinking skills, and difficulty learning 
mathematics.

\section{RESULT AND DISCUSSION}

Table 1. Data of survey

\begin{tabular}{|c|c|c|c|}
\hline \multirow[t]{2}{*}{ School } & \multicolumn{3}{|c|}{ Component of survey } \\
\hline & First capability & Kebiasaan belajar & Hobby \\
\hline SMP 16 & The concept of a flat and triangular shape & $90 \%$ study together & Sports and play \\
\hline SMP 23 & The concept of a flat and triangular shape & $74 \%$ self study & Sports \\
\hline SMP 13 & The concept of a flat and triangular shape & $90 \%$ study in tutoring institutions & Sports and play \\
\hline
\end{tabular}

The data in table I shows that the average student has a sports hobby, most students like sports such as soccer and basketball, but the rest like water sports like swimming, badminton, volleyball, and others. So in the next stage, commercial sports video games are chosen based on the most results, namely football or basketball.

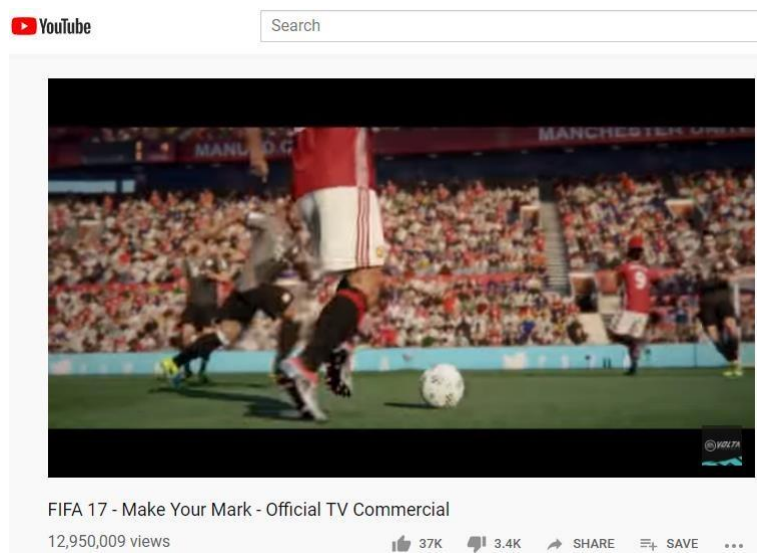

Figure 2. Commercial Sport Video Games 1

In video games 1 is a TV ad that shows soccer players from the beginning before entering the field, playing, until score. The TV ad is titled FIFA 17 - Make Your Mark. Students are asked to interpret the video from the title to the end of the video.

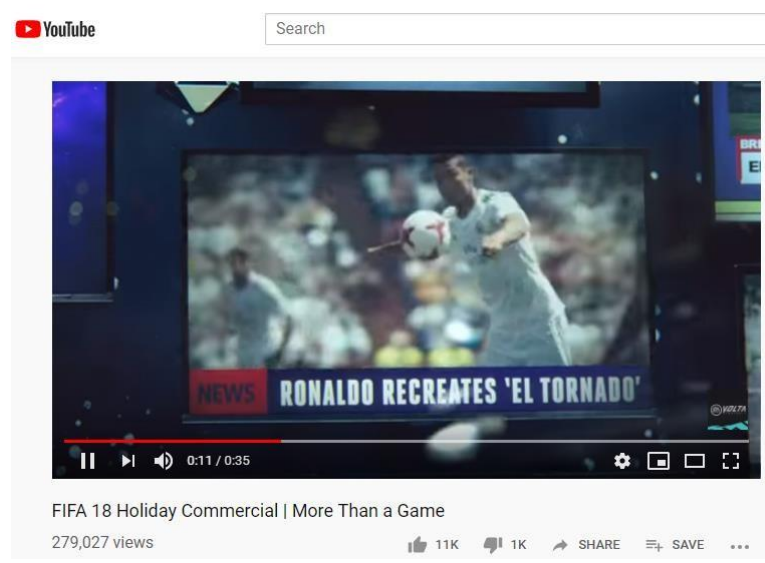

Figure 3. Commercial Sport Video Games 2

In video games 2 , it is a holiday advertisement, which shows soccer videos in a television shop and is accidentally seen by men passing in front of the store. The TV ad is titled FIFA 18 holiday Commercial. As in the first video, students also asked to interpret video from title to the end of the video. 
This work is licensed under a Creative Commons Attribution-ShareAlike 4.0 International License.

Furthermore, the preparation of the interview guide was prepared based on the task of commercial sports video games. Both assignments ask students to retell the video by proposing and solving visible problems.

Table 2. Result of SMPN 16 (Subject S1)

\begin{tabular}{|c|c|c|c|}
\hline \multirow{2}{*}{ Subject } & \multicolumn{3}{|c|}{ Indicator and Result } \\
\hline & Indicator & Video 1 & Video 2 \\
\hline \multirow[t]{5}{*}{ S1 } & Similarity & Football & Football \\
\hline & Distinction & Reality & Taping \\
\hline & Variabel & $\begin{array}{l}\text { Footballer }(k) \text {, audience }(m) \text {, crowd }(c) \text {, } \\
\text { substitute player }(n)\end{array}$ & $\begin{array}{l}\text { People }(n) \text {, television }(p) \text {, interests } \\
\text { (b), videos played (q) }\end{array}$ \\
\hline & Modelling & $\begin{array}{l}c=11 k+30 m ; \\
c=(11 k-n)(11 k+n)+30 m\end{array}$ & $b=n+5 p$ atau $b=q p+5 p$ \\
\hline & Solution & $\begin{array}{l}\text { Suppose the value of } k \text { and } m \text { to find the } \\
\text { value } c\end{array}$ & $\begin{array}{l}\text { Suppose the values of } n \text { and } p \text { to } \\
\text { find the value of } b\end{array}$ \\
\hline
\end{tabular}

S1 shows several variables in video one and video two, which are different even though they have similarities about football. Modeling is made of two kinds, first based on the player and audience variables, the second based on substitute players entering and leaving the field. While the solution obtained by assuming an arbitrary value on each variable with positive integers.

In interpreting the first video, S1 describes the soccer player having a target to make a mark on him by scoring goals so that he will be famous. The atmosphere of the match will crowd if anyone can put the ball into the opponent's goal. Whereas S1 interprets video two by stating that renowned soccer players like Ronaldo are making people outside the shop interested in video shows on the television.

Table 3. Result of SMPN 16 (Subject S2)

\begin{tabular}{|c|c|c|c|}
\hline \multirow{2}{*}{ Subject } & \multicolumn{3}{|c|}{ Indicator and Result } \\
\hline & Indicator & Video 1 & Video 2 \\
\hline \multirow[t]{5}{*}{ S2 } & Similarity & Football & Football \\
\hline & Distinction & Playing football in the stadium & Ronaldo was on TV \\
\hline & Variabel & $\begin{array}{l}\text { Stadium }(s) \text {, football player }(p) \text {, audience } \\
(a) \text {, football field }(k) \text {, ball }(b)\end{array}$ & $\begin{array}{l}\text { Television }(\mathrm{t}) \text {, audience }(\mathrm{a}) \text {, } \\
\text { store }(\mathrm{s})\end{array}$ \\
\hline & Modelling & $X=s+11 p+20 k+b$ & $y=t+a+s$ \\
\hline & Solution & $\begin{array}{l}\text { Enter the value of a known variable to } \\
\text { find the value of variable } X\end{array}$ & $\begin{array}{l}\text { Enter an arbitrary value on the } \\
\text { variables } t, a \text {, and } s \text { to find the } \\
\text { value of variable } y\end{array}$ \\
\hline
\end{tabular}

S2 shows several variables in video one and video two, which are different even though they have similarities about football. He mentioned three variables seen in both videos. They made modeling in the form of linear equations. Whereas the solution obtained by assuming an arbitrary value on each variable with positive integers, just as did the first subject.

In interpreting video 1, S2 elaborates on the height of the stadium, perhaps because there is a favorite soccer player who has become a champion. They hope that these players can play best and can score goals against the opponent. Towards the end of the video, it appears that one of the players seemed to be giving a sign of victory. Whereas in interpreting video 2 , he mentioned that people who watched the video on television were interested in Ronaldo's game which might be his favorite player. 
This work is licensed under a Creative Commons Attribution- ShareAlike 4.0 International License.

Table 4. Result of SMPN 16 (Subject S3)

\begin{tabular}{|c|c|c|c|}
\hline \multirow{2}{*}{ Subject } & \multicolumn{3}{|c|}{ Indicator and Result } \\
\hline & Indicator & Video 1 & Video 2 \\
\hline \multirow[t]{4}{*}{ S3 } & Similarity & Football & Football \\
\hline & Distinction & Reality in football stadium & $\begin{array}{l}\text { a man sees a football video in a } \\
\text { television shop }\end{array}$ \\
\hline & Variabel & football player $(p)$, audience $(a)$, ball (b) & Television (t), man (m) \\
\hline & $\begin{array}{l}\text { Modelling } \\
\text { Solution }\end{array}$ & $\begin{array}{l}\text { Enter the varnablet values } p \text {, } a \text { and } b \text { to } \\
\text { find the value of variable } X\end{array}$ & $\begin{array}{l}\text { Entet Walues in the variables } t \text { and } \\
m \text { to find the value of variable } y\end{array}$ \\
\hline
\end{tabular}

S3 shows several variables in video one and video two, which are different even though they have similarities about football. Modeling is made using linear equations with variables of soccer players, soccer, and spectators. While the solution obtained by assuming an arbitrary value on each variable with positive integers.

In interpreting video one, S3 describes the situation in a football stadium that shows that there are soccer players, spectators, and balls contested by players. Beginning with preparation of the players, the exit of players to the field, followed by the game of football. The game ends with the victory of one of the teams with the red costumed player giving a sign of success to the audience. Whereas in video two, he mentioned that the television shop was playing a football game with the famous player Ronaldo so that someone would watch.

\section{Discussion}

All three subjects showed the same answer in the aspects of similarity and solution because all three liked soccer. These answers are following what is in the scheme and finding a solution to a linear equation is usually done by specifying any particular number or parameter to get the desired variable value.

Table 5. Students difficulty

\begin{tabular}{|c|c|c|c|}
\hline Subject & Observing Video games & Writing answers & Answer the question The \\
\hline S1 & $\begin{array}{c}\text { Subjects watched videos } 1 \\
\text { and } 2 \text { with pleasure and } \\
\text { enthusiasm }\end{array}$ & $\begin{array}{l}\text { The answers are written } \\
\text { coherently and model two } \\
\text { forms }\end{array}$ & $\begin{array}{l}\text { subject answered questions } \\
\text { smoothly on each } \\
\text { indicator }\end{array}$ \\
\hline S2 & $\begin{array}{c}\text { Subjects watched videos } 1 \\
\text { and } 2 \text { with pleasure and } \\
\text { enthusiasm }\end{array}$ & $\begin{array}{l}\text { The answers are written } \\
\text { with a little question from } \\
\text { the researcher about the } \\
\text { need to write the symbol }\end{array}$ & $\begin{array}{l}\text { The subject answers } \\
\text { questions doubtfully on the } \\
\text { modeling and solution } \\
\text { indicators }\end{array}$ \\
\hline S3 & $\begin{array}{c}\text { Subjects watched videos } 1 \\
\text { and } 2 \text { with pleasure and } \\
\text { enthusiasm }\end{array}$ & $\begin{array}{l}\text { The answer was not } \\
\text { immediately written down, } \\
\text { but he paused } \\
\text { remembering what was } \\
\text { seen in the video }\end{array}$ & $\begin{array}{l}\text { The subject answered the } \\
\text { questions in the order of the } \\
\text { indicator quite smoothly but } \\
\text { asked many questions. }\end{array}$ \\
\hline
\end{tabular}

The three subjects began to show differences in writing differences, many variables, modeling. For the aspect of distinction, subjects S1, S2, and S3 write the same about reality on video 1 , but for video 2 , there is a short sentence. For the variable aspect, most write football players, but in $\mathrm{S} 1$ he had time to think about a substitute player, while others did not write the player. Aspects of modeling, almost all write the form of linear equations, but S1 also print the form of quadratic equations.

All indicators or aspects shown by the three subjects show the ability to think innovation by showing the novelty of how to construct mathematical models with self-determined variables of the objects seen in both videos.

All students who initially have difficulty learning, they can answer correctly. These answers are due to video games about sports making them interested and not bored with 
This work is licensed under a Creative Commons Attribution-ShareAlike 4.0 International License.

mathematics. They said that seeing commercial sports video games helped eliminate boredom and made it hard for them to learn.

During their work on watching commercial sports video games to answering questions during the interview, they looked happy and enjoyed the lesson. These task-based interviews were consistent with previous research which states that lessons can be combined with entertainment to make learning meaningful. They have a mathematical experience that does not make it difficult for them to learn but makes them entertained and encourages innovative thinking.

\section{CONCLUSION}

Subjects S1, S2, and S3, who respectively had high, moderate, and low levels of difficulty showed innovative thinking skills after watching commercial sports video games. They can mention all the indicators that appear after seeing the shows. These indicators are similarity, distinct, variable, modeling, and solution. They also could learn mathematics meaningfully from the sentence that they made.

\section{ACKNOWLEDGMENT}

The author would like to thank the parties who helped carry out this research, namely from the school namely the Head of SMP 16 along with mathematics teachers and students of class VIII. We also thank SMP 23 and SMP 13 for assisting in the initial survey of our research.

\section{REFERENCES}

Beaty, R. E., Benedek, M., Silvia, P. J., \& Schacter, D. L. (2016). Creative Cognition and Brain Network Dynamics. Trends in Cognitive Sciences. https://doi.org/10.1016/j.tics.2015.10.004

Beckman, S. L., \& Barry, M. (2007). Innovation as a learning process: Embedding design thinking. California Management Review.

Bourgonjon, J., Valcke, M., Soetaert, R., \& Schellens, T. (2010). Students' perceptions about the use of video games in the classroom. Computers and Education. https://doi.org/10.1016/j.compedu.2009.10.022

Brown, M., Brown, P., \& Bibby, T. (2008). "I would rather die": Reasons given by 16-year-olds for not continuing their study of mathematics. Research in Mathematics Education. https://doi.org/10.1080/14794800801915814

Granic, I., Lobel, A., \& Engels, R. C. M. E. (2014). The benefits of playing video games. American Psychologist. https://doi.org/10.1037/a0034857

Ojose, B. (2008). Applying Piaget's theory of cognitive development to mathematics instruction. The Mathematics Educator, 18(1). (2008). Applying Piaget's theory of cognitive development to mathematics instruction. The Mathematics Educator.

Phaire, C. B. (New Y. U. (2001). Video Games and Mathematics Education: Studying Commercial Sports Video Games to Identify the Potential for Learning and Thinking About Mathematics. In D. (UNC C. Pugalee \& D. (UNC C. Royster (Eds.), Mathematics Education in the 21st Century (pp. 1993-1995). Charlotte, NC.

Sadera, W. A., Li, Q., Song, L., \& Liu, L. (2014). Digital Game-Based Learning. Computers in the Schools. https://doi.org/10.1080/07380569.2014.879801

Siswono, T. Y. E. (2010). LEVELING SSiswono, T. Y. E. (2010). LEVELING STUDENTS' CREATIVE THINKING IN SOLVING AND POSING MATHEMATICAL PROBLEM. Journal on Mathematics Education. https://doi.org/10.22342/jme.1.1.794.17-40TUDENTS' CREATIVE THINKING IN SOLVING AND POSING MATHEMATICAL . Journal on Mathematics Education. https://doi.org/10.22342/jme.1.1.794.17-40

Timmons, V., \& Cairns, C. (2010). Case study research in education. In Encyclopedia of Case Study Research. 


\section{:: IJEEIT ::}

(International Journal of Electrical Engineering and Information Technology)

Weber, K. (2002). STUDENT DIFFICULTY IN CONSTRUCTING PROOFS : THE NEED FOR STRATEGIC KNOWLEDGE. Educational Studies in Mathematics.

What Video Games Have to Teach Us about Learning and Literacy. (2004). Education + Training. https://doi.org/10.1108/et.2004.00446dae.002 